\title{
Microfluidic devices for X-ray studies on hydrated cells
}

\author{
Britta Weinhausen and Sarah Köster*
}

\author{
Received Xth $X X X X X X X X X X 20 X X$, Accepted $X$ th $X X X X X X X X X 20 X X$ \\ First published on the web Xth $X X X X X X X X X X 200 X$ \\ DOI: 10.1039/b000000x
}

\begin{abstract}
X-ray studies of biological cells in microfluidic devices provide a method to probe cellular structures or structural changes at the molecular level in a precisely controlled environment. However, the device design and the used materials must be compatible with X-ray scattering techniques as well as the cell culture in the devices. For this purpose, we develop new types of X-ray compatible microfluidic devices, which are based on a UV-curable adhesive as a moldable material, and thin Kapton films and silicon nitride membrane windows as growth substrate for cells and as window material for X-rays. Using these devices, we perform scanning X-ray diffraction experiments with a nano-focused beam on fixed cells in buffer solution. In principle, these microfluidic devices also allow for X-ray studies on living cells.
\end{abstract}

\section{Introduction}

The combination of X-ray scattering techniques with sample chambers or delivery systems based on microfluidics provides a versatile toolbox to access structures or structural changes at the molecular level in an adaptable and well-defined sample environment. However, in X-ray studies the well-established microfluidic devices based on soft lithography ${ }^{1}$, which are often used in combination with optical microscopy, bring about the problem of showing a high X-ray absorption and a strong background signal in the small-angle region ${ }^{2}$.

To meet the requirements of X-ray scattering experiments, a variety of microfluidic devices based on different materials and fabrication techniques has been proposed in the past as reviewed by Köster and Pfohl ${ }^{2}$. One example are devices built of adhesive Kapton film as window material and a thin film of a moldable polymer like polydimethylsiloxane (PDMS), which defines the channel geometry ${ }^{3,4}$. Despite the good properties of Kapton film in X-ray studies, the adhesive layer can lead to problems in terms of background scattering or bio-incompatibility depending on the specific experimental parameters. An interesting approach using Kapton as window material is also presented by Barrett et al. ${ }^{5}$. Here, the microfluidic devices are built of two Kapton films and the channels are written directly into the Kapton film using laser ablation. A further example for microfluidic devices used in combination with X-ray studies are devices, which are completely built of the UV-curable Norland Optical Adhesive 81 (NOA 81) ${ }^{6}$. Sophisticated channel structures can easily be molded in NOA 81 and briefly cured layers of NOA 81 can be

Institute for X-Ray Physics \& Courant Research Centre "Nano-Spectroscopy and X-Ray Imaging”, Georg-August-Universität Göttingen, Friedrich-HundPlatz.1,37077 Göttingen, Germany. E-Mail: sarah.koester@phys.unigoettingen.de; Fax: +49 (0)551399430; Tel: +49(0)551399429 attached to each other, allowing for the fabrication of multilayered devices. However, severe radiation damage to this material restricts the use of this device type at high photon flux synchrotron beamlines. Additional limitation in device design and material choice arise for specific requirements of the studied objects. Living cells are probably among the most challenging samples as they need well-defined growth conditions like temperature or $\mathrm{pH}$ value, continuous nutrient supply and, in the case of adherent cells, also a specific substrate.

In this paper we report on the fabrication of new types of $\mathrm{X}$-ray compatible microfluidic devices for experiments on hydrated and potentially also living cells. The channel structure is laterally defined in a layer of NOA 81. The top and bottom of the channel are open in the NOA 81 layer and the channel is sealed by two thin Kapton foils (with no additional adhesive). Optionally, even thinner silicon nitride $\left(\mathrm{Si}_{3} \mathrm{~N}_{4}\right)$ membrane windows can be inserted and used as a growth substrate for cells. Further, $\mathrm{Si}_{3} \mathrm{~N}_{4}$ membrane windows are an ideal window material for X-rays as they provide low X-ray absorption, high radiation resistivity and no background scattering in the small-angle region. Device fabrication, cell culture and the set-up used for scanning X-ray diffraction experiments are described in section 2. In section 3, results from X-ray experiments on fixed cells in microfluidic devices, as a first step towards experiments on living cells in these devices, are presented and discussed. Finally, a conclusion and an outlook are given in section 4 .

\section{Materials and methods}

\subsection{Microfluidic device fabrication}

Microfluidic devices are fabricated in a multi-step process, which is a further development of the process described by 


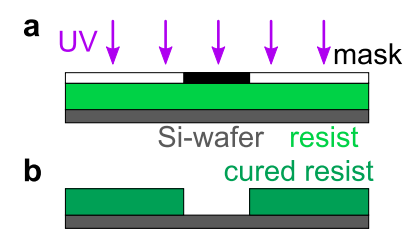

C PDMS
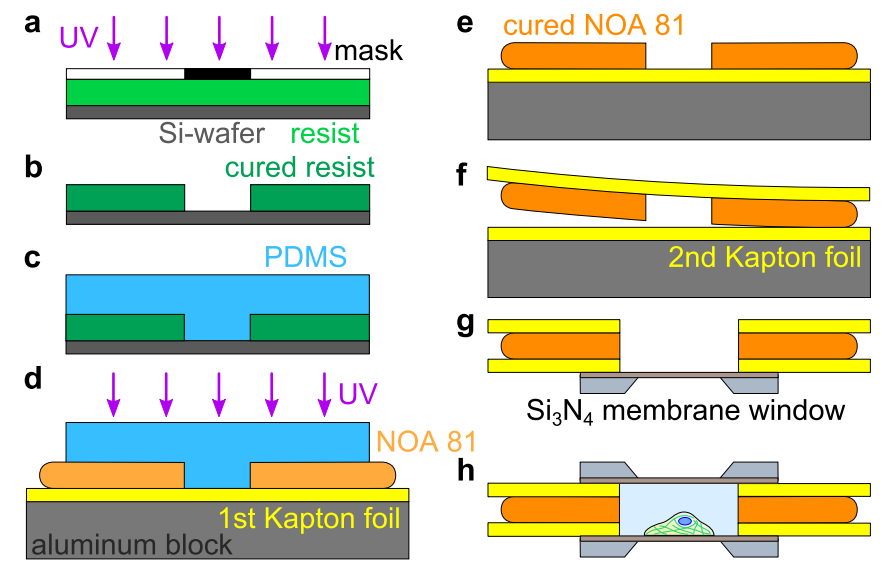

f

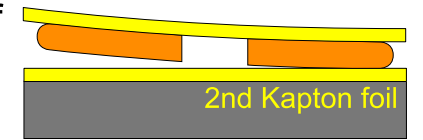

g

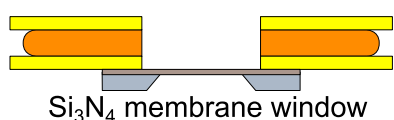

h

$\mathrm{Si}_{3} \mathrm{~N}_{4}$ membrane window

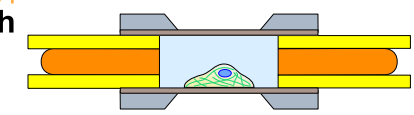

Fig. 1 Schematic overview of the device fabrication. (a) A thin layer of photoresist is spin-coated on a silicon wafer and exposed to UV-light through a mask. (b) Upon development of the resist, previously non-exposed regions become channels in the resist. (c) A PDMS stamp is cast from the wafer. (d),(e) A piece of Kapton foil is attached to a flat aluminum block and a drop of NOA 81 is pipetted on the Kapton foil. The PDMS stamp is put on the NOA 81 and is pushed down until the channel touches the Kapton foil. NOA 81 is cured by exposure to UV-light and the PDMS stamp is removed. (f) A second Kapton foil is attached to another aluminum block. The Kapton foil with the NOA 81 film is removed from the aluminum block and carefully put on the second Kapton foil. (g) A hole is punched through the device in the center of the channel and one side is sealed with a $\mathrm{Si}_{3} \mathrm{~N}_{4}$ membrane window. (h) Cells are grown on the window and, after cell fixation or after they are attached well, the device is closed with a second $\mathrm{Si}_{3} \mathrm{~N}_{4}$ membrane window.

Brennich et al. ${ }^{6}$. A master for the device fabrication is produced by photolithography using SU-8 negative resist (SU8 3050, MicroChem, Newton, MA, USA) as shown in Fig. 1a,b. The resist is spin-coated on a polished silicon wafer (SilChem, Freiberg, Germany) at $1000 \mathrm{rpm}$ yielding a layer thickness of about $130 \mu \mathrm{m}$, exposed to UV-light through a photomask and developed. Here, as design a straight channel with a width of $500 \mu \mathrm{m}$ is chosen, but virtually any geometry is possible. Channel height, width and geometry can be easily adapted to specific requirements by choosing a different spinning speed, resist or photomask. The wafer with the cured resist as shown in Fig. 1b is vapor-coated with (heptafluoropropyl)-trimethylsilane (Aldrich, Steinheim, Germany), which enables a smooth removal of the PDMS stamp produced in the next step.

PDMS stamps (Sylgard 184, Dow Corning, Midland, MI, USA) are cast from the wafer as shown in Fig. 1c. A circular piece of $8 \mu \mathrm{m}$ thick Kapton foil (SPEX SamplePrep, Metuchen, NJ, USA) is attached via capillary forces to a flat aluminum block by applying a small drop of isopropanol between the Kapton foil and the aluminum block. Wrinkles in
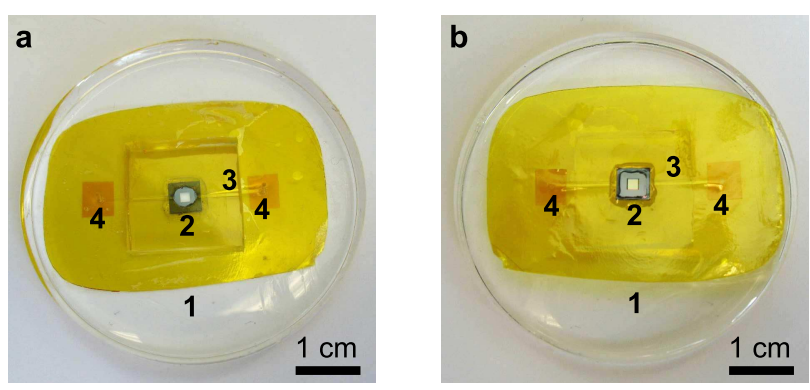

Fig. 2 Photographs of a microfluidic device with one $\mathrm{Si}_{3} \mathrm{~N}_{4}$ membrane window attached to the Kapton foil. (a) View on the inside of the chamber, in which the cells are grown and measurements are performed. (b) View on the outside of the device. (1) PDMS support with a hole in the center, (2) $\mathrm{Si}_{3} \mathrm{~N}_{4}$ membrane window, (3) channel, (4) inlet/outlet, which are sealed from one side with Kapton tape, for the connection of tubings and syringe pumps.

the foil are removed with a tissue and excess isopropanol is squeezed out, until the Kapton foil is tightly attached to the aluminum block. $100 \mu 1$ NOA 81 (Norland, Cranberry, NJ, USA) are pipetted each onto the Kapton foil and onto the structure on the PDMS stamp and air bubbles are removed with a small pipette tip. The stamp is placed on the Kapton foil and pushed down until the elevated channel on the PDMS stamp touches the Kapton foil as shown in Fig. 1d, which assures that the channel is only laterally defined by NOA 81 , while the top and bottom are open in the NOA 81 layer. NOA 81 is cured by exposure to UV-light for $2 \mathrm{~min}(8 \mathrm{~W}$ at $365 \mathrm{~nm})$, which leaves a thin layer of NOA 81 at the NOA 81/PDMS interface uncured ${ }^{6-8}$ and therefore allows for sealing the device with a second Kapton foil with no need for an additional glue or adhesive. This way, we avoid glue clogging the channels.

The PDMS stamp is carefully removed leaving the cured NOA 81 film on the Kapton foil (see Fig. 1e) and a second Kapton foil is attached to another aluminum block as described above. The Kapton foil with the NOA 81 film is removed from the aluminum block and attached with the NOA 81 side to the second Kapton foil as shown in Fig. 1f. If $\mathrm{Si}_{3} \mathrm{~N}_{4}$ windows are to be incorporated, a hole is punched through the device in the center of the channel using a Harris UniCore $^{\mathrm{TM}}$ puncher (Plano, Wetzlar, Germany) with a diameter of $3.5 \mathrm{~mm}$, which determines the lateral size of the chamber. The device is glued to a PDMS support allowing for connection to a syringe system as described by Brennich et al. ${ }^{6}$.

The hole in the device is closed from one side with a $\mathrm{Si}_{3} \mathrm{~N}_{4}$ membrane window (frame: $5 \times 5 \mathrm{~mm}^{2} \times 200 \mu \mathrm{m}$, membrane: $1.5 \times 1.5 \mathrm{~mm}^{2} \times 1 \mu \mathrm{m}$; Silson Ltd., Blisworth, England). For this purpose, the $\mathrm{Si}_{3} \mathrm{~N}_{4}$ membrane window is first placed on a small PDMS block, to which it attaches via capillary forces. Loctite polyolefin primer 770 (Henkel, Düsseldorf, Germany) is applied locally around the hole in the device at one side and 
Loctite 406 (Henkel) is applied with a small pipette tip to the outermost part of the frame of the $\mathrm{Si}_{3} \mathrm{~N}_{4}$ membrane window. The window is positioned on the hole (see Fig. $1 \mathrm{~g}$ ) by holding the PDMS block with a pair of tweezers and the PDMS block is subsequently removed. Additionally, the edges of the $\mathrm{Si}_{3} \mathrm{~N}_{4}$ window are sealed with a two-component glue (UHU plus schnellfest, UHU, Bühl, Germany). Fig. 2 shows photographs of the device from both sides at this stage of the fabrication process. The second $\mathrm{Si}_{3} \mathrm{~N}_{4}$ membrane window is attached in the same manner after the cells are grown on the first membrane window, resulting in a chamber as shown in Fig. 1h, which is connected to an inlet and an outlet channel.

\subsection{Cell culture}

SK8/K18-2 cells are generously provided by Rudolf Leube (RWTH Aachen, Germany). The cells are derived from human adrenal cortex carcinoma cells (SW-13 cells ${ }^{9}$, ATCC CCL105), which are stably transfected with DNA encoding for fluorescent human keratin hybrids (HK8-CFP, HK18-YPF) ${ }^{10-12}$. The cells are cultured in high glucose ( $4.5 \mathrm{~g} / \mathrm{l})$ Dulbecco's Modified Eagle Medium (PAA Laboratories GmbH, Pasching, Austria) with $10 \%$ Fetal Calf Serum (Invitrogen $\mathrm{GmbH}$, Darmstadt, Germany), $100 \mathrm{U} / \mathrm{ml}$ Penicillin and $0.1 \mathrm{mg} / \mathrm{ml}$ Streptomycin (Sigma-Aldrich, Munich, Germany) at $37^{\circ} \mathrm{C}$ in a water saturated atmosphere with $5 \% \mathrm{CO}_{2}$.

For microfluidic experiments, the devices (Fig. 1g) are cleaned with $70 \%$ ethanol and sterilized with UV-light for $30 \mathrm{~min}$. Culture medium is filled into the hole in the PDMS to cover the $\mathrm{Si}_{3} \mathrm{~N}_{4}$ membrane (see Fig. 2a), cells suspended in medium are added, and the cells are incubated for 1-2 days ${ }^{13}$. Afterwards the cells are briefly washed with phosphate buffered saline (PBS), fixed by adding 4\% formaldehyde solution (Sigma-Aldrich, Munich, Germany) for $15 \mathrm{~min}$ at room temperature and washed three times with PBS. Phase contrast and epifluorescence microscopy images of the whole $\mathrm{Si}_{3} \mathrm{~N}_{4}$ membrane are taken at an inverted microscope (IX 71, Olympus, Hamburg, Germany) equipped with $10 \times$ and $20 \times$ objectives. The sample chamber is sealed with a second $\mathrm{Si}_{3} \mathrm{~N}_{4}$ membrane window directly before the $\mathrm{X}$-ray diffraction experiments.

\subsection{X-ray diffraction and microfluidic experiments}

X-ray diffraction experiments are performed at the Göttingen endstation GINIX ${ }^{14,15}$ at the P10 beamline at PETRA III (DESY, Hamburg, Germany). The undulator beam is adjusted to a photon energy of $7.9 \mathrm{keV}$ using a double crystal $\mathrm{Si}(111)$ monochromator and focused in horizontal and vertical directions by Kirkpatrick-Baez-mirrors to a size of about $360 \times 280 \mathrm{~nm}^{2}(\mathrm{FWHM})$ with a primary beam intensity of $10^{11} \mathrm{photons} / \mathrm{s}$. The microfluidic device is connected to pre- cise syringe pumps (neMESYS, Cetoni GmbH, Korbußen, Germany) and PBS is pumped through the device at a constant flow rate of $100 \mu \mathrm{l} / \mathrm{h}$, corresponding to a mean flow velocity of $\approx 0.4 \mathrm{~mm} / \mathrm{s}$. Subsequently, the device is mounted on a sample stage and aligned in the X-ray focus using a calibrated visible-light microscope. Behind the sample, the radiation passes through an evacuated flight tube and the primary beam intensity is attenuated by two semi-transparent beamstops. The intensity is recorded on a Pilatus $300 \mathrm{k}$ detector $\left(487 \times 619\right.$ pixels, pixel size: $172 \times 172 \mu \mathrm{m}^{2}$; Dectris Ltd., Baden, Switzerland) at a sample-to-detector distance of $5.22 \mathrm{~m}$. Two-dimensional mesh scans are performed on the sample and at each point a scattering pattern is recorded. This allows for the generation of real-space images by employing different contrast types ${ }^{16-18}$ as well as the analysis of individual diffraction patterns ${ }^{19}$.

\section{Results and discussion}

Two challenging steps in the preparation for microfluidic experiments on cells are (i) bringing adherent cells into closed channels and (ii) supplying the not yet adhered cells with nutrients without washing them out of the channels. By growing cells on the $\mathrm{Si}_{3} \mathrm{~N}_{4}$ membrane window glued to the device bottom while the device is still open, we circumvent these problems. The very clean surface of the $\mathrm{Si}_{3} \mathrm{~N}_{4}$ membrane windows allows for finding the cells with comparatively low-resolution bright-field microscopes used for sample alignment at beamlines. Further, $\mathrm{Si}_{3} \mathrm{~N}_{4}$ membrane windows combine the characteristic of being a good substrate for cell growth with having excellent properties during X-ray experiments. In this study we use a low flow rate to perfuse the sample without exerting shear stress on the cells, but higher flow rates can be applied without detachment of the Kapton foil from the NOA 81 layer.

From the scanning X-ray diffraction experiments, X-ray dark-field images are calculated by masking the primary beam on the detector and integrating the scattered intensity for each scattering pattern. These total intensity values are arranged in a two dimensional array yielding a real-space image of the sample. Fig. 3c shows an X-ray dark-field image obtained from a scan with a step size of $500 \mathrm{~nm}$ on one part of the cell in the center of the visible-light phase contrast and fluorescence microscopy images in Fig. 3a,b. Despite the low electron density difference of about $0.1 \mathrm{e}^{-} / \AA^{3}$ between cellular material and water ${ }^{20}$, the cell can clearly be imaged using X-ray darkfield contrast and even thin extensions of the cell are visible. For comparison, for freeze-dried samples an electron density difference between protein and air of about $0.4 \mathrm{e}^{-} / \AA^{3}$ is obtained ${ }^{20}$. During the whole experiment, the device is stable in position within the accuracy of the scan.

However, one problem we do notice during the measure- 


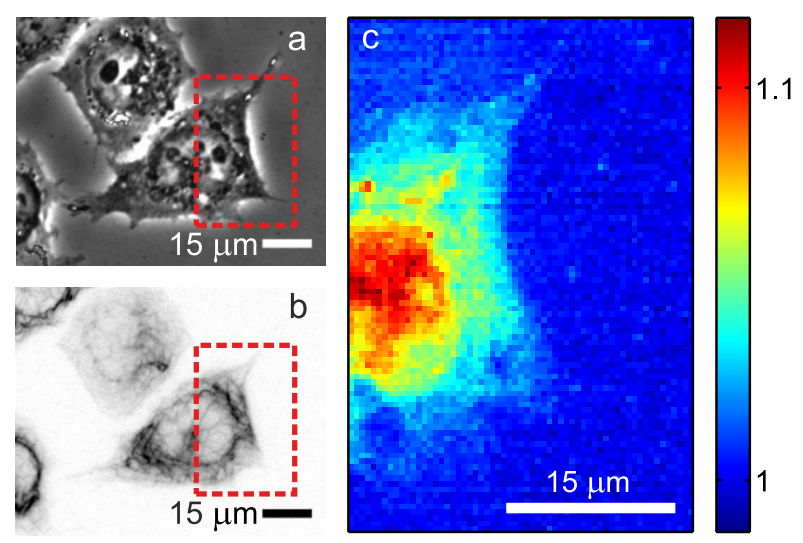

Fig. 3 (a) Visible-light phase contrast and (b) fluorescence microscopy image of SK8/K18-2 cells. (c) X-ray dark-field image of the marked part of the cell in the center of the microscopy images.

ment, is the formation of gas bubbles in the sample chamber. These bubbles increase very fast in size when the sample is exposed to X-rays and seem to stay constant in size inbetween two measurements. Higher flow velocities in combination with broader channels might help to reduce the rate of increase of the gas bubbles by removing the small bubbles before coalescence.

\section{Conclusion}

We develop new types of X-ray compatible microfluidic devices based on the UV-curable glue NOA 81 as a moldable material, $8 \mu \mathrm{m}$ thick Kapton foil, and $\mathrm{Si}_{3} \mathrm{~N}_{4}$ membrane windows as growth substrate for cells. We show that it is possible to grow and fix cells on the $\mathrm{Si}_{3} \mathrm{~N}_{4}$ membrane windows while the device is still open and close the device with a second $\mathrm{Si}_{3} \mathrm{~N}_{4}$ membrane window directly before the X-ray measurements. Scanning X-ray diffraction experiments are performed on fixed cells in the device. Here, it is possible to reconstruct $\mathrm{X}$-ray dark-field images from hydrated cells even though the electron density difference between cellular material and water is very low.

The presented method of sample preparation in principle also allows for enclosing living cells in the device and supplying them with nutrients via the inlet and outlet channels, while performing X-ray studies. First proof-of-principle experiments to probe the effects of hard X-rays on living cells can be performed even without any further modification.

We also suggest to build microfluidic devices for X-ray experiments on non-adherent cells or fluid samples, like protein solution, as described in section 2.2 but without inserting $\mathrm{Si}_{3} \mathrm{~N}_{4}$ membrane windows. In this case, the window material for the X-rays is $8 \mu \mathrm{m}$ thick Kapton foil, which is also highly resistant to radiation and produces - due the low film thickness - only a weak small-angle scattering signal. These devices would further guarantee a well-defined flow-field throughout the whole device allowing for time- or concentration-depended experiments ${ }^{6,21}$.

\section{Acknowledgements}

We thank Michael Sprung, Tim Salditt, Martin Krenkel, Marius Priebe, Marten Bernhardt, and Malte Vaßholz for their help and support during synchrotron beamtime at P10, PETRA III and Rudolf Leube, Anne Kölsch, and Reinhard Windoffer for providing the transfected SK8/K18-2 cells. This work was supported by the German Research Foundation (DFG) in the framework of SFB 755 "Nanoscale Photonic Imaging" and the Excellence Initiative. B.W. is supported by a fellowship of the Deutsche Telekom Stiftung.

\section{References}

1 Y. Xia and G. M. Whitesides, Annu. Rev. Mater. Sci., 1998, 28, 153-184.

2 S. Köster and T. Pfohl, Mod. Phys. Lett. B, 2012, 26, 1230018.

3 R. Dootz, H. Evans, S. Köster and T. Pfohl, Small, 2007, 3, 96-100.

4 H. M. Evans, R. Dootz, S. Köster, B. Struth and T. Pfohl, Bulletin of the Polish Academy of Science - Technical Sciences, 2007, 55, 217-227.

5 R. Barrett, M. Faucon, J. Lopez, G. Cristobal, F. Destremaut, A. Dodge, P. Guillot, P. Laval, C. Masselon and J.-B. Salmon, Lab Chip, 2006, 6, 494-499.

6 M. E. Brennich, J.-F. Nolting, C. Dammann, B. Nöding, S. Bauch, H. Herrmann, T. Pfohl and S. Köster, Lab Chip, 2011, 11, 708-716.

7 C. Decker and A. D. Jenkins, Macromolecules, 1985, 18, 1241-1244.

8 S. A. Stern, V. M. Shah and B. J. Hardy, J. Polym. Sci. B Polym. Phys., 1987, 25, 1263-1298.

9 A. Leibovitz, W. B. McCombs, D. Johnston, C. E. McCoy and J. C. Stinson, J. Natl. Cancer Inst., 1973, 51, 691-697.

10 P. Strnad, R. Windoffer and R. E. Leube, J. Cell Sci., 2002, 115, 4133 4148.

11 R. Windoffer, S. Wöll, P. Strnad and R. E. Leube, Mol. Biol. Cell, 2004, 15, 2436-2448.

12 S. Wöll, R. Windoffer and R. E. Leube, Eur. J. Cell Biol., 2005, 84, 311 328.

13 J. Sedlmair, S.-C. Gleber, S. O. Mert, M. Bertilson, O. von Hofsten, J. Thieme and T. Pfohl, Microsc. Microanal., 2011, 17, 991-1001.

14 S. Kalbfleisch, H. Neubauer, S. P. Krüger, M. Bartels, M. Osterhoff, D. D. Mai, K. Giewekemeyer, B. Hartmann, M. Sprung and T. Salditt, AIP Conference Proceedings, 2011, 1365, 96-99.

15 T. Salditt, S. Kalbfleisch, M. Osterhoff, S. P. Krüger, M. Bartels, K. Giewekemeyer, H. Neubauer and M. Sprung, Opt. Express, 2011, 19, 9656-9675.

16 G. R. Morrison and M. T. Browne, Rev. Sci. Instrum., 1992, 63, $611-614$

17 M. D. de Jonge, B. Hornberger, C. Holzner, D. Legnini, D. Paterson, I. McNulty, C. Jacobsen and S. Vogt, Phys. Rev. Lett., 2008, 100, 163902.

18 P. Thibault, M. Dierolf, C. M. Kewish, A. Menzel, O. Bunk and F. Pfeiffer, Phys. Rev. A, 2009, 80, 043813.

19 B. Weinhausen, J.-F. Nolting, C. Olendrowitz, J. Langfahl-Klabes, M. Reynolds, T. Salditt and S. Köster, New J. Phys., 2012, 14, 085013.

20 H. B. Stuhrmann and A. Miller, J. Appl. Crystallogr., 1978, 11, 325-345.

21 S. Köster, H. M. Evans, J. Y. Wong and T. Pfohl, Biomacromolecules, 2008, 9, 199-207. 